Policy, Practice and Innovative Governance in the English Further Education and

Skills Sector.

Dr Andrew Clapham*

Dr Rob Vickers

School of Education

Nottingham Trent University

Clifton Lane

Nottingham

NG11 8NS

* Email: andrew.clapham@ntu.ac.uk 


\section{Policy, Practice and Innovative Governance in the English Further Education and}

\section{Skills Sector.}

Dr Andrew Clapham*

Dr Rob Vickers

School of Education

Nottingham Trent University

This paper examines 'innovative' governance in English Further Education and Skills (FE) sector. Drawing on the work of Lyotard (1977), Foucault (1979) and Ball (2003), the paper explores how practitioners enacted innovative governance in a sector facing increasingly performative conditions. Analysis identified the key category of opportunity and risk where innovative governance was seen as paramount in leading change and changing practice. Innovative governance was not a 'golden bullet', rather, innovation was a complex set of interrelated understandings, strategies, values and norms. The paper concludes by suggesting that, in the cases reported here, innovative governance was at the forefront of defending the very essence of FE during a time of extraordinary funding, and philosophical, challenge.

Keywords: innovative; governance; performativity; policy; enactment

\section{Introduction}

This paper explores 'innovative governance' in the English Further Education and Skills sector (FE) during a time of significant financial challenge. It mobilises the work of Lyotard (1977), Foucault (1979) and Ball (2003) which examines neo-liberalism and performativity in public sector education settings to explore practitioners' enactment ${ }^{1}$ of innovative governance. The paper drills-down into innovative governance in practice and its relationship to the increasingly performative environment facing the English public

\footnotetext{
${ }^{1}$ Policy is enacted by those in context rather than implemented by those external to that context see Ball et al (2012).
} 
sector. Analysis of data generated from principals, chairs, governors and clerks suggested that innovative governance had a significant role in creating opportunity, mitigating risk and leading change to both organisations and practice.

The paper reports on the findings from the Innovative Governance in FE project (InnGov) funded by the Further Education Trust for Leadership (FETL). InnGov considered how innovative governance played out for close to 150 different corporation members across 24 organisations. InnGov examined innovative governance over the twelve-month period from April 2015 to April 2016 - a time period which proved to be particularly significant for English FE. For example, in February 2015, the then Skills Minister Nick Bowles, illustrated what was to become the Conservative government's FE policy narrative:

There will be some difficult choices to take about the less productive bits of our further education system, about those programmes where maybe we can expect more from the individuals taking the programme in terms of their ability to contribute to the funding of them. (Bowles, 2015, no page)

It is within this context of 'difficult choices' that this paper examines how FE governors, chairs, principals and clerks defined and enacted innovative governance. It should be noted that the English FE sector is a comparatively - at least for a setting that had an annual budget of $£ 3.9$ billion in 2015-16 - under researched area (although see, Child, 2009; Feather, 2012). So as to contribute to the area of FE research, the paper explores innovative governance within a sector increasingly facing accountability, marketisation and performative technologies such as inspection.

Despite the importance of the 2015 funding cuts, and LAR policy initiative, financial and policy challenges facing FE governance did not begin in 2015. In 1999, Gleeson and Shain, discussed how the 'current crisis of governance' (558) reflected the wider policy landscape in which the FE then found itself. Fast forward more than ten 
years, and Gleeson et al, $(2011,793)$ wrote of creative governance being a means of resistance toward 'external agendas at odds with local priorities'.

However, 2015 did signal major policy and financial decisions. In early 2015, the UK government announced a reduction of $24 \%$ in funding for FE in England. As a consequence Martin Dole, the AOC Chief Executive, (2015, no page) suggested that there would be 190,000 fewer FE places in 2016 with the result that 'adult education and training is effectively being decimated'.

Moreover, 2015 saw Local Area Reviews (LAR) become a high-stakes policy narrative. LAR was instigated by the Department for Business, Innovation and Skills (BIS) and Department for Education (DfE) and resulted in a rapid series of policy enactments. For example, on the $8^{\text {th }}$ of September 2015, BIS and DfE published the document Post-16 education and training institutions: area based reviews which set out the framework for LARs. On $15^{\text {th }}$ September 2015, twenty two general FE colleges were identified as those included in the first round post-16 education and training area reviews. On $19^{\text {th }}$ October 2015, the then FE Commissioner David Collins, reported on this first wave of reviews.

\section{Towards a definition of innovative governance}

It was within the 2015 policy environment, that the paper examined innovative governance in FE. However, pinning down a working definition of innovative governance from the literature proved to be problematic. Gleeson et al $(2011,781)$, suggest that governance is 'best defined in the contexts, cultures and situations in which it is located...[it] does not operate in a vacuum'. Consequently, there is no a 'one-size-fitsall' approach to defining innovative governance. Although 'innovation' and 'governance' have been examined in the settings of economics, business and politics, innovative 
governance and governance per se is an under-researched area of activity in FE (although see, Parnham, 1998; Gleeson 1999; Gleeson et al, 2011).

Parnham (1998) for example, suggests that governance in concerned with the establishment of policies, and the continuous monitoring of their effective implementation, by the members of the governing body of an organisation. The Oxford English Dictionary defines innovation as ' 1 . Something newly introduced, such as a new method or device. 2. The act of innovating'. Whereas the Organisation for Economic Cooperation and Development (OECD), defined innovation as:

...the implementation of a new or significantly improved product (good or service), or process, a new marketing method, or a new organisational method in business practices, workplace organisation or external relations. (OECD and Eurostat, 2005: 46)

In all cases, 'newness' is prominent in the definition. However, innovation is more than the implementation of new ideas, knowledge and practices - innovation is crucially related to improved ideas, knowledge and practices (see Kostoff, 2003; Mitchell, 2003). Innovation is not merely reform or change, as change does not necessarily mean the application of something new, nor is change necessarily the application of improved ideas or knowledge (King and Anderson, 2002).

King and Anderson (2002) highlight that innovation governance, is widely used within the business and corporate world. In these settings, innovation is the process of translating an idea or invention into a good or service that creates value, or for which customers and service users will pay. Correspondingly, Deschamps (2014) has conceptualised innovation governance as a system of mechanisms to align goals, distribute resources and assign decision-making power for innovation.

From examining the literature, there are clear resonances which underpin the definitions of innovative and governance. What is prominent in the evidence base is that 
in a range of settings outside of FE and education, innovative governance is an area of interest and research. Indeed, think tanks such as The Centre for International Governance Innovation and The Centre for the Study of Governance Innovation have been established to influence policy makers to innovate and re-think social, political and economic governance. Similarly, the United Nations (2006) have promoted 'Innovations in Governance' with the aim of facilitating states to face new challenges and transfer effective practices.

From considering the evidence base, this paper defines innovative governance as 'a means of considering and facilitating transition and positive change as a Board that will benefit the organisation as a whole'.

\section{Governance in the English FE sector}

FE governance is bound by statutory powers of law and this primary FE governance legislation is supported by the Instruments and Articles which define the responsibilities and practice of governing bodies. The governing body (also known as 'the Board', or 'the Corporation') has various responsibilities (AOC, 2013):

(a) Statutory responsibilities include the employment of staff, the offer of various services and the ownership of assets.

(b) Contractual obligations exist with the College's staff, learners and suppliers.

(c) Common law duties include loyalty, good faith, care, diligence and skills exercised by governors due to their fiduciary position on a College's governing body.

All FE Colleges were incorporated under the 1992 Further and Higher Education Act with the 2011 Education Act giving greater levels of flexibility. However, the 2011 
Act also led to significantly greater levels of accountability and scrutiny. Because all General FE Colleges are charities, governors must also adhere to the Charities Act 2011. The increasingly high-stakes nature of FE as a policy narrative has not left the responsibilities of governance, and governors, unnoticed by ministers. Writing in 2013 Mathew Hancock, the then Minister for Skills, outlined that:

The Government has promised to secure greater rigour and responsiveness in further education. To this end, it has freed colleges from central government control, and reinforced the increasingly important role of college governors in setting the strategic direction of their institutions. These changes give colleges greater autonomy - but they also bring increasing accountability to the students, employers and wider communities which they serve. (Hancock, 2013, 3)

The narrative of empowerment, responsibility and accountability in governance was similarly echoed by Hancock’s successor Nick Bowles:

The governing body is responsible for the strategic oversight of the college and are guardians of public money, ensuring its effective and efficient use. As such, governing bodies should have the right mix of skills and experience to fulfil these responsibilities. They should be empowered to ask the difficult questions and to make sure they have the information and data they need to challenge and scrutinise the executive and hold the Principal to account. (Bowles, 2014, 1)

The BIS guidelines in which Bowles was writing highlighted a significant change in the direction of travel of policy regarding FE accountability in England. The 2014 guidelines also signalled the underlying FE policy direction. A direction which furthered the decentralised nature of FE governance, whilst giving more localised powers to governors and with it demanding increased evaluation, inspection and accountability.

\section{Innovative governance and performativity}

Performativity (Lyotard, 1979; Ball, 2003) is a lens which has previously been focussed upon post-compulsory education (see, Avis and Bathmaker, 2004: Elliott, 2012; 
Mulcahy, 2004; Orr, 2009). Performativity is the 'optimisation of the global relationship between input and output' (Lyotard, 1979, 11). The neo-liberal marketisation of public sector has led to the implementation of accountability technologies originally seen in commercial situations to be applied to policing, health and education contexts (Ball, 2012).

For Lyotard $(1979,15)$, measurable indicators or 'regulatory mechanisms' are inherent in performativity as are the high-stakes outcomes of regulatory mechanisms such as inspection (Ball, 2003). Accountability is achieved through the use of metrics to represent the efficiency of an organisation - in this case FE governance - and which are mapped against both benchmarks and competitors (Perryman et al, 2011). Crucially, the disciplinary and transformative elements of performativity lead external regulatory systems such as inspection to be embedded in the practice of those within the organisation (see Perryman, 2006; 2009).

For Ball (2003), performative self-regulation has resulted in conditions where inspectors, policy makers, ministers and the market define the work of those within educational settings. Self-regulatory measures, reflect the neo-liberalisation of in general education systems (Lyotard, 1979) and within the learning and skills sector (James and Biesta, 2007).

Ball (2008) suggests that within performative conditions governance merely reflects the state's neo-liberal centralised control of the delivery of state services. Moreover, within performative discourses, the public sector is often portrayed as 'broken' and in need of 'fixing' with the private sector being positioned as the means to do the fixing (Ball, 2012). This of course ignores the financial, social and economic disasters which have been a direct consequence of the private sector's drive for success in the neo- 
liberal market (the global banking crisis; Volkswagen emissions testing; payment protection insurance).

Performativity, and performative reform, at the macro-scale results in a 'global education policy' (Ball, 2012, 115) whilst at the micro-scale becomes 'totally inscribed in general and essential transformations' (Foucault, 1979, 139). The consequence of these micro and macro scale performative structures is the rise of what Ball $(2012,113)$ calls metagoverance. In metagovernance, the performative technologies of inspection, marketisation, and private sector models of leadership become imbued into day-to-day practices - with the result that what were once seen as fragmented and fragmenting practices become part of the neo-liberalisation of education, governance and the state itself.

So as to explore innovative governance acknowledgement needs to be made of the performative context in which FE governance, and FE in general, operates. As such, micro-scale enactments of policy discourses - such as how informants employed innovative governance to negotiate the LAR process - are examined so as to explore increasingly prevalent macro-scale neo-liberal structures (see Clapham, 2015a; 2015b; 2015c).

\section{Methodology and analysis}

The project employed a qualitative methodology and asked three research questions:

- What is meant by innovative governance?

- How does innovative governance play out in performative conditions?

- What can innovative governance offer in relation to opportunity and risk? 
The British Educational Research Association (BERA, 2011) ethical framework was adopted to ensure anonymity and protection of the informants all of whom self-selected to participate ${ }^{2}$. The project was set predominantly in the East Midlands of England although there were contributions from a wide range of national and international informants. The project team worked closely with the East Midlands Further Education Council (EMFEC) to access FE organisations and their governing Boards of its community of 26 member colleges.

The East Midlands region contains a mixture of FE colleges, Sixth Form, specialist and land- based, from which governors and principals were drawn as informants and as members of the Project Steering Group (Table 1).

\section{TABLE 1 HERE}

Table 1. Type and number of colleges involved in project

Data were generated from principals $(n=10)$, chairs $(n=14)$, governors $(n=77)$, staff governors $(n=8)$, student governors $(n=3)$, clerks $(n=12)$ and non-FE governors $(n=11)$ as well as across a cross section of $(n=24)$ of FE colleges (Table 2).

\section{TABLE 2 HERE.}

Table 2. Project Informants

2 All informants and organisations mentioned in this paper are pseudonyms to provide confidentiality. 
The primary data generation tool was through reflexive interviewing which acknowledges that interviewing is a social practice (Kvale and Brinkman, 2008). In reflexive interviewing, the process is recognised as (a) laden with ethical issues (b) embedded in social and historic context (c) involves asymmetrical power relationships between interviewer and interviewee. Reflexive interviewing was an important approach for the project, due to the sensitive and confidential nature of the conversations and the professional standing of those being interviewed.

So as to achieve trustworthiness (Guba and Lincoln, 1994), Denzin's (1970) method triangulation was employed. Interview data were supplemented by data generated through an on-line survey and focus group. The on-line survey $(n=70)$ was also conducted so as to obtain as wide a range of possible responses to the three research questions. The focus group consisting of principals, chairs, governors and clerks $(n=10)$ who were part of a Regional Governors Network Meeting was instigated so as to cross-check the four categories which emerged from the analysis (see Table.3).

The project employed grounded theory as the analytical framework. From mobilising grounded theory literature (Glaser and Strauss, 1967; Strauss and Corbin, 1998; Charmaz, 2005), analysis consisted of coding data and the identification of concepts and categories. In this process, concepts were phenomena which emerged from the data and categories linked groups of similar phenomena together (Table. 3). Through the grounded theory process, coding of data informed future areas of investigation. Grounded theory coding was not a distinct and singular stage, but a continuous part of the analytical process.

\section{TABLE 3}


Table 3. Grounded theory analysis

There were two distinct phases for the project.

1. Scope the field and identify categories

2. Interrogate innovative governance policy and practice within categories

Phase 1 consisted of an initial literature review, interview with key stakeholders, interview with project steering group, interviews with principals, chairs, governors and clerks and a focus group consisting of principals, chairs, governors and clerks who were not part of the interview process. As illustrated in Table 3, the analytical process identified four categories ${ }^{3}$ :

- Opportunity and risk

- Purpose of Further Education

- Social justice

- Local/ national/ international economy

This scoping process additionally resulted in the identification of three key lenses with which to examine the four categories:

- The range of people

- Process and decision making

- Collaboration and structures

The informants in the initial scoping exercise generated data which highlighted the importance of these three lenses in governance. Consequently, these lenses were used

\footnotetext{
${ }^{3}$ Due to space considerations, only the Opportunity and Risk category will be considered in this paper.
} 
as a reference when asking question so as not to lose focus amongst the wide range of data being generated.

\section{Findings and discussion}

Analysis led to the development of five 'think pieces' which were shared with the national FE governor community. The five think pieces reflected different aspects of the project trajectory as well as the understandings as to what innovative governance was, and how it played out, for the informants.

- Think Piece One set out the four innovative governance categories

- Think Piece Two mobilised the three lenses to examine the four innovative governance categories

- Think Piece Three set examined how innovative governance could bring about change in relation to the four innovative governance categories

- Think Piece Four set out the four examined informants reports as to how innovative governance played out in practice in their organisation relation to the four innovative governance categories

- Think Piece 5 developed an innovative governance self-evaluation tool

Rather than examine each of the five think pieces individually, the paper will instead focus on three 'headline' findings which map across all five think pieces:

1. What makes innovative governance: people, collaboration, structures

2. Innovative governance - leading change

3. Innovative governance - changing practice 


\section{What makes innovative governance: people, collaboration, structures}

Governors told us that innovative governance required a mindset which deliberately reviewed practice, considered change, and identified areas of success. Key in the data, was that innovative governance should not merely perpetuate a historical governance approach. Moreover, innovative governance included a series of complex interactions between a variety of stakeholders and institutions.

The context within which innovative governance was exercised was crucial, for example, the central role governors played within the LAR process ${ }^{4}$. What was clear in the data was that despite - or because of - the high-stakes, high-pressure policy context facing FE, overwhelmingly informants felt that innovative governance could help their institutions to improve:

I think that innovative governance is all about finding new ways of doing things better, as opposed to the way things happened in the past. (Tim, Governor)

...by using innovation we can have the same or even less effort and time, but improve the output or outcomes. (Nicola, Governor)

There was also a wide ranging consensus that 'freeing up' space to think about and debate innovation could have a valuable impact upon the FE sector:

...from a governance point of view, innovative to me means a freedom and an ability to express one's opinions. (Sandy, Chair)

Governors reported that their Boards needed to be, and in the most part were, open to and capable of innovation. Wrapped up in this general understanding of innovative

\footnotetext{
${ }^{4}$ The BIS (2015) guidance on LAR sets out that the governing body of every FE and Skills institution will be expected to take an active role in the local LAR steering group through the chair of governors, who will be key members of each local group.
} 
governance however was the relationship between innovation and opportunity and risk. For example, Michael, a governor suggested that:

Governing bodies need to look out as well as inwards to the college. The best governors do it to bring connectivity with other spheres that are helpful for the thriving of the organisation.

Informants felt that FE Boards should not be risk averse, and that by being innovative governors could help create new opportunities whilst mitigating risk. Data suggested that governors felt they had a key role to play in managing risk by supporting, and scrutinising, the actions of the senior management team. Focus group members suggested that in order to facilitate the management of opportunities and risks, Boards required individuals who could:

(a) recognise the need for change

(b) were adept at reacting to a changing environment

(c) lead strategic transformation of organisations

Central to innovative governance therefore was being able to understand risks, and being prepared to accept that some risks are worth taking. As Eve, an expert in the voluntary sector, observed:

...the private sector can be characterised as managing risk in order to take risk, and old style public sector characterised as having a focus on managing risk in order to avoid risk.

Participants highlighted the importance of governors helping FE institutions to embrace new opportunities and that collaboration with other institutions was a way of achieving this. The form that collaboration should take was viewed differently however, 
ranging from sharing ideas to amalgamating resources. Karen suggested that providers should not stand apart from other institutions, instead:

...get to know them, understand their weaknesses, their strengths, the things they do well. (Karen, Clerk)

However, some governors expressed concern at a lack of innovation surrounding potential collaboration:

We should share experiences beyond the boundaries of the college. But in my college, governors only look inwards to our college, not strategically beyond. (Anne, Governor)

Anne continued by indicating that a balance of looking both outward and inward needed to be played out in meetings. So too, a balance between reactive 'rear-view' monitoring of performance and proactive forward thinking.

For the informants, innovative governance meant being open minded and deliberately, and creatively, considering change. Crucially however innovation was a relative term, as practice which might be considered innovative at one institution could be customary elsewhere. As a result, sharing experiences amongst governors both internal and extremal to a Board was considered an innovative approach. Collaboration in innovative governance was perceived as being a continuum that could facilitate innovation ranging from informal sharing of ideas through to federations and mergers.

\section{Innovative governance: leading change}

Central in the data was that change through innovative governance had to fundamentally benefit the informants' FE institutions and stakeholders. Informants made it clear that a Board did far more than solely scrutinise decisions. However, some governors suggested that a compliance culture meant that a governor's job increasingly became one of checking accountability: 
I think the role of a governing body in FE up to now has been pretty securely anchored in the rear view mirrors environment. (Fay, Governor)

...governance is so much more about compliance and check lists, structures rather than approaches and practice. (Sam, Governor)

However, compliance culture was increasingly seen as integral to the instruments and articles of governance. Nonetheless, informants emphasised that a key role for the Board was to set the strategic aims, values and standards of the institution they govern:

We should be doing strategic thinking, and focusing on what direction the College could or should be taking, and using our time for looking forward. (Eric, Chair)

These data point to governors having a dual role in bringing about change through (a) setting the direction that their institution was to take and (b) overseeing the way in which this was carried out. For many of the governors, the vital role of effective leadership in successfully initiating and adapting to change was fundamental to innovative governance.

Many reasoned that utilising innovative approaches to governance could assist Boards to take advantage of opportunities and respond to risks. Moreover, they emphasised that their role was to lead change at their institution via strategic thinking, rather than by merely planning. By taking responsibility for strategic thinking, Boards free the executive to concentrate on day-to-day management of the organisation:

...the executive should focus upon running the business - making the College successful, and not be distracted by worrying about what might happen. They shouldn't be distracted from the Colleges main business, which is education. (Philip, governor)

While the majority of governors viewed strategic thinking as primarily the Board's concern, Clair felt that this should be founded upon delivering the central mission of the institution for which they are responsible: 
It is much more I think about strategic thinking, rather than the planning. Because surely planning is more of a management type role, but it is even more than that, it is about going back to sort of basics in what is the purpose of the organization you are responsible for. Which I think must come before strategy, because strategy really is a tool isn't it; it is a tool to so something. (Clair, governor)

What was clear from the data, was that informants felt that the constituent conditions for innovative governance were interconnected. This interconnection meant that innovative governance had to be taken forward in an integrated, and coordinated, manner in order to bring about effective and beneficial change. Wrapped up in the concept of change, was how informants reported that FE was in a period of greatly heightened risk and financial pressures and faced the prospect of significant transition and changes in the future.

Governors felt that they had a key role to play in successfully responding to this policy landscape by concentrating on strategic thinking and leadership of the FE system. Prominent in the data was the need for careful thinking and review of the right balance of organisational interests with the wider policy narrative - as one informant, Nicky said the impetus should be on "thriving rather than surviving".

However, informants were adamant that the policy landscape did not play out evenly and different providers had different needs in terms of governance. While there was no universally agreed definition of what 'good' should look like governance (although see Schofield 2009a; 2009b), as it is dependent on context, it was evident that innovative approaches to governance could help Boards to create and take opportunities and mitigate risks.

\section{Innovative governance: changing practice}

Innovative governance change, and importantly positive change, was a central part of the informants' data. Informants reported that InnGov had stimulated conversation not only 
about what innovative governance might look like, but also about how innovative governance could work within FE. The most prominent suggestions and recommendations which governors made relating to innovation and change could be summarised by three key considerations.

\section{Governors needed to ask questions about the way governors govern: a process that}

presented the possibility of introducing innovation that could enhance governance.

A key consideration was the importance of asking questions about the way a Board governs. Indeed, asking such questions presented the possibility of introducing innovation that could enhance governance. Some governors suggested it was important for Boards to continually consider ways of improving their governance practices:

Keeping governance under review means that we are open to change to get the best out of governance. (Peter, Governor)

Peter continued by stressing that this was:

...not just changing governance for its own sake, but for the scale and types of challenges we have. Just introducing some changes makes us think about our governance and how we want it to be and to develop.

Like Peter, Stephen, maintained that there was a clear justification for introducing meaningful innovation:

I think that governors of $\mathrm{FE}$ colleges really have an opportunity in this environment, with a lot of changes taking place within the education sector to bring more of a corporate mentality to the running of a college. Now I don't mean all the bad things to do with the corporate world, and there are many bad things, rather things such as an independent mind set, there are clear processes in place in terms of decision making. (Stephen, governor)

Other governors argued that not questioning current practice, and being unwilling to innovate, was an inherently risky approach. There was a concern that a significant number 
of colleges were facing challenges identified via OfSTED inspections with governance being a major challenge for a number of providers.

2. Each Board member needed to be well informed about the institution which they were responsible for, and understood its purpose

There was a broad ranging consensus that it was advantageous for governors to be well informed about the college for which they were responsible. One way of achieving this was to have an induction process that provided an understanding of the systems that governors were working within. As Jane, a Company Secretary and advisor to several Boards, noted:

Because I could get, I don't know, the finance director from a multi-million pound private company who is good, but they would have to be able to apply their knowledge within what works in the sector. And I could have someone with a mass of teaching experience, but they still have to understand it within the sector that we work within.

Some governors suggested that a good way for Board members to get to know how a college functioned was to have broad ranging discussions with stakeholders. For example, there was a suggestion that governors could hold open surgeries for staff and students:

As long as it is understood they are not there to be advocates, they just begin to understand the whole culture, the whole system, and I have done that in the past and it can be very beneficial. It can open their eyes quite honestly, you know I didn't realise we were doing this, or why didn't someone tell me that. I think that there are more positives than negatives, so I think they have got to know the institution for which they are guardians essentially. (William, governor)

Similarly Samir, a Chair of Governors, remarked that the Board on which he served jointly came to the realisation they were not talking enough about teaching, learning and assessment:

That all the Board had to take responsibility and really understand teaching, learning and assessment. Now we have teaching, learning and assessment as the first part of every corporation meeting, and we have a range of ways in which we 
do this e.g. department head comes and talks through the strengths, weaknesses, opportunities and risks in their area - and the governors are clear that we do not want sugar coating but the real picture. We want problems or risks to be out in the open so that they can be addressed. This was a culture change for the college both for governance and the senior managers and means that we are on a proper footing now.

As a result, innovative governance had to both acknowledge the Board's statuary requirements to take an objective view on practice, whilst also being part of the organisation as a whole. Marrying thee two elements were seen as crucial if, as one governor outlined, "...the left hand is to know what the right hand is doing".

\section{Boards required governors to be open to innovation and change, and not risk averse.}

Many respondents clearly stated the importance of governors being open to change. The consensus was that innovative governance included being open to considering new ways of governing that was best for the strategic context. Moreover, informants highlighted that it was vital that governors, chairs, clerks and principals had an open mind-set around what governance was, should be, and could be.

There was considerable reference to the financial and performative climate facing FE. As a result of the resulting financial pressures, informants felt that the role of collaborative governance, whether strategic alliances, federations or mergers had to be considered so that there was a viable, vibrant and high quality network of FE colleges. As Mike highlighted:

The financial pressures may mean that without those kinds of developments some colleges will 'fall by the wayside' and so a wider strategic response is needed. The process of governance can be staid and not necessarily get the best from the combination of skills and wisdom in governors and therefore the collective decision making of the corporation may be sub optimal. The usual format of agenda business meetings are only one way and part of the way for having effective 
governance. Corporations also need diversity and divergent thinkers as part of leading innovative colleges, and valuing and drawing on this well is essential.

The notion that Boards should not be risk averse, and should be willing to take calculated risks was again a prominent theme:

Investment in innovation can be very wise and prudent, and risks are to be managed. Governance should not be anti-risk. However, in practice, sometimes college governors can see prudence leading to a mid-set of protection of assets, rather than asserts being there to be invested to make the biggest difference to our local people. (Peter, Governor)

Some governors spoke of the need for an appetite for risk particularly in times of significant change where they reported there was a tendency for people to 'pull up the drawbridge' which was considered the incorrect course of action.

Innovation in governance therefore was outward looking and mindful of the need to acknowledge changes in practices. However, innovative governance also had to acknowledge the risks which organisations faced. Whist this might appear an obvious statement, what was clear in the data was that there was a denial culture in some organisations. This denial culture again mapped strongly to the rear-view forward-view metaphor discussed earlier. Clear in the data was that innovative governance was linked to managing risk and that embracing and negotiating risk was only possible if risk was first acknowledged.

\section{Discussion}

This paper aimed to examine innovative governance and the relationship between innovative governance and performativity. In doing so, it has covered a lot of ground everything from openness and relationships to risk and risk avoidance. Starting with perhaps the most obvious of these aims, analysis suggests that for governance to be 
innovative it must be a means of considering and facilitating transition and positive change as a Board that will benefit the organisation as a whole.

The two words positive and benefit here are key. For governance to be innovative it cannot simply instigate change. Innovative governance must lead to positive change, change that is not siloed, and change which benefits the entire organisation. However, there are considerable meta-levels which need to be considered even with this definition. For example, there was considerable debate amongst participants regarding the difference between good and innovative governance. This debate struck at the heart as to what governance was, and was for.

Informants reported that 'good' governance had been hijacked by performative discourses relating to inspection grading. This hijacking had the corollary that innovative governance had to be positioned, and justified, within inspection facing requirements. Unfortunately for many informants, it was just this narrow performative context which led to the very risk adverse practices which they maintained inherently prevented good, and outstanding, governance from taking place.

For the purpose of this paper we have called the practice of risk avoidance 'rearview governance', where the focus of the Board was on one thing and one thing only the looming presence of OfSTED. Indeed, many governors reported that OfSTED had become so inscribed in the day-to-day narratives, discourses and actions of their organisations that everything that happened - from the displays in the foyers, to the curriculum and budget allocations - was undertaken with the view as to how it would be received by inspectors.

Similarly, analysis has led to 'innovative-thinking' versus 'innovative-actions'. Informants were adamant that innovative governance must be more than just a buzz word or seen as something new and 'trendy' which governors had to do. As such, innovative- 
action could be seen as superficial, with one informant describing it as "...getting rid of desks, sitting on bean bags and eating pizza". This was stark contrast to the deep-seated understandings, relationships, discourses and process which emerged from innovativethinking. In contrast to innovative-action, innovative-thinking was proactive and included long-term planning whereas innovative-action was characterised by reactive and short term 'firefighting'.

The paper has focussed specifically on the relationship between innovative governance and opportunity and threat. What is important here is that despite the policy environment facing FE, overwhelmingly governors still saw opportunities to make their practice, and their organisations, better. Participants maintained that innovative governance led to organisations that were flexible, nimble and 'fleet of foot' with regard to the policy environment in which they operated. Crucially, innovative governance mediated the opportunity for Boards to be outward, not solely, inward looking. In doing so, this outward view led to opportunities for alliances with stakeholders, and other institutions, which were mutually beneficial. However, these alliances could only occur if Boards were innovative enough to create and value such external connections.

Innovative governance also developed opportunities through re-appraising decision making structures. This point comes with the caveat however, that such reappraising needing to be situated in innovative-thinking not just innovative-action. For example, fixed agendas were identified as not necessarily conducive to innovative governance, nor were agendas which were only developed by a small number of Board members - especially those agendas which were seen to be the sole domain of the Clerk - and Board meetings that took place over many hours. Recurring in the data was that innovative governance had to encompass flexibility in decision making structures. 
Wrapped up in this flexibility was the key concept of strategic direction. Innovative governance must be able to respond to change and see these changes as opportunities. Again, there is an important caveat here - respondents reported that flexibility in policy strategy was what they felt should happen, however, for the vast majority this was not what was happening.

How innovative governance maps, and does not map, to policy strategy leads to the potential risks associated with being innovative. The headline finding however highlighted that the only risk which informants associated with innovative governance was not being innovative. There were of course stipulations associated with being innovative, for example, risk should always be mediated, or 'hedged'. However, as one governor put it “...if you stand still you will be swallowed up". It seemed that innovative governance by its very nature was seen as neither risk adverse nor reckless.

What emerged from this project was the degree to which governance was shaped, performed and evaluated in performative terms. Governance has already been mentioned in relation to the hijacking of 'good' and 'outstanding' governance by inspection discourses and the effect of this hijacking upon innovation. However, the relationship between performativity and governance is subtler than semantics. In the introduction, the policy context during which this project took place highlighted the LAR process. In many ways, LAR was the epitome of a market-driven performative approach to education.

However, surprisingly at first, LAR featured seldom if at all in the data. After reinterrogating the analysis however, it became clear as to why this was the case. Governors saw LAR simply as the next in a continuous line of amendments, restructuring and policy redevelopments facing the FE sector. LAR was simply just the next big change. Governors highlighted that LAR was "on the radar" but not an immediate priority. Some 
Boards had 'cleared their desks' ready for LAR but as one governor stated "in FE you always have to roll with the punches".

This acceptance of the continually changing policy narrative facing FE, perhaps explains the universal acceptance of innovative governance as a 'good thing' by the study informants. It also explains why LAR was not the primary topic of conversation in the Board meetings examined here. Ball $(2012,115)$ writes of the rise of a 'global education policy' located in neo-liberal marketization and performativity. As stated earlier, Ball also writes of metagoverance (113).

From examining the work of governors, it seems that those in this study were acutely aware of metagovernance and the associated performative technologies of inspection, marketisation, and private sector models of leadership. Not only were they acutely aware, but they saw innovative governance as a way of navigating the policy discourse in a way that was most beneficial to their organisation.

Of course, simplistically stating that a Board is going to become innovative flattens the complexity of the policy environment. Governing bodies are bound by mandatory instruments of governance and procedures that are part of the organisation's public accountability. In contrast to these structures however, is that innovative governance is not constrained by any of the formal instruments of governance. Rather, for Boards to be innovative it is the established cultures and everyday practices which need to be successfully negotiated.

\section{Innovative governance, a case of "thriving not just surviving"?}

Perhaps the primary finding regarding innovative governance is an obvious one openness to new ideas is the first step in the innovation process and without such openness innovative governance fails. By continually questioning the way they functioned, Boards were able to introduce the possibility of improving their approach to governance. 
Moreover, the Board's culture was of vital importance. Boards with a transparent approach toward its own functions and processes was felt to have a far greater propensity for innovation than those that were not transparent. Significantly, governors felt that they were the leaders of the culture and set the tone for the rest of the organisation.

Open and transparent governance was not possible without strong, trusting and respectful professional relationships. Indeed, such relationships were central to effective governance per se not just when considering innovative governance. However, these relationships had to be evident across all facets of the governance structure. It was detrimental for governors to have excellent professional relationships, but not governors and the clerk, or governors and the Chair. Moreover, there had to be effective working relationship between the governors, the senior management team and the Clerk. Again, the notion of embracing risk was seen as critical. Many of the governors argued that the real risk was failing to innovate in response to a changing environment

If innovative governance meant anything to the governors in this study it seemed to mean hope. Despite the extraordinary - and seemingly never-ending - challenges facing the sector, governors passionately believed in FE. They also passionately believed in the strategic role of innovative governance in negotiating, at least as best as possible, the threats and challenges which faced their organisations. It is important to be clear. The one thing that governors were most passionate about was the students and the chances FE gave to those learners.

Innovative governance is much more than the processes of innovative-action, such as the introduction of new technologies or the development of new programmes. Innovative governance facilitates positive transition and change which benefits an entire organisation. In doing so, such governance appears to circumnavigate some of the macro- 
level economic, political and performative structures which have loomed in the FE sector's rear-view mirror over, at least, the last 15 years.

\section{References}

AOC, 2013, Creating Excellence in College Governance. London: AOC.

AOC. 2015. Governance briefing -03/15 Adult education and training provision. Available at: http://www.aoc.co.uk/publications/governance-briefing-0315. Accessed 20/3/15.

Avis, J., and Bathmaker, A-M. 2004. Critical pedagogy, performativity and a politics of hope: trainee further education lecturer practice, Research in Post Compulsory Education, 9(2): 301-316.

Ball, S. 2003. The teacher's soul and the terrors of performativity. Journal of Education Policy 18(2): 215-228.

Ball, S. 2008. New philanthropy, new networks and new governance in education, Political Studies, 56: 747-765.

Ball, S. 2012. Global Education Inc. New Policy Networks and the Neo-Liberal Imaginary. London: Routledge.

Ball, S., Maguire, M., and Braun, A. 2012. How Schools Do Policy: Policy Enactments in Secondary Schools Abingdon: Routledge.

Bowles, N. 2014. Foreword. College Governance: A guide. Department for Business Innovation and Skills (BIS). London: BIS. https://www.gov.uk/government/uploads/system/uploads/attachment_data/file/3 44615/BIS-14-1012-college-governance-a-guide.pdf. Accessed 18/3/16.

Bowles, N. 2015. Bowles: government faces 'difficult choices' over future of colleges. Times Education Supplement. https://www.tes.com/news/further- 
education/breaking-news/boles-government-faces-difficult-choices-over-futurecolleges. Accessed 18/3/16.

British Educational Research Association. 2011 Ethical guidelines for educational research.

http://content.yudu.com/Library/A1t9gr/BERAEthicalGuideline/resources/index htm?referrerUrl=http\%25253A\%25252F\%25252Fwww.yudu.com\%25252Fite m\%25252Fdetails\%25252F375952\%25252FBERA-Ethical-Guidelines-2011 accessed 9/7/14.

Charmaz, K. 2005. Grounded Theory in the 21st Century. In N. Denzin and Y. Lincoln (Eds.), Handbook of Qualitative Research (3rd ed.). Thousand Oaks: Sage.

Child, S. 2009. Differing relationships to research in higher and further education in the UK: a reflective account from a practitioner perspective, Research in PostCompulsory Education, 14(3): 333-343.

Clapham, A. 2015a. Post-fabrication and putting on a show: examining the impact of short notice inspection. British Educational Research Journal. 41(2): 613-682.

Clapham, A. 2015b. Producing the docile teacher: analysing Local Area Underperformance Inspection. Cambridge Journal of Education. 45(2): 265-280.

Clapham, A. 2015c. "Answer your names please": a small scale exploration of teachers technologically mediated 'new lives'. Teachers and teaching. Theory and Practice. 21(6): 366-378.

Deschamps, J., and Beebe, N. 2014. Innovation Governance: How Top Management Organizes and Mobilizes for Innovation. London: Wiley.

Delamont, S. 1976. Beyond Flanders Fields: The Relationship of Subject Matter and Individuality to Classroom Style. In Explorations in Classroom Observation, M. Stubbs, and S. Delamont (Eds), 101-131. London: John Wiley and Sons. 
Elliott, G. 2012. Policy, performativity and partnership: an ethical leadership perspective, Research in Post-Compulsory Education, 17(4): 423-433.

Feather, D. 2012 Do lecturers delivering higher education in further education desire to conduct research? Research in Post-Compulsory Education, 17(3): 335-347.

Foucault, M. 1979. Discipline and Punish: The Birth of the Prison London: Penguin

Gleeson, D., and Shain, F. 1999. By Appointment: governance, markets and managerialism in further education. British Educational Research Journal. 25(4): $545-561$.

Gleeson, D., Abbott. A, and Hill. R. 2011. Governing the governors: a case study of college governance in English further education. British Educational Research Journal. 37(5): 781-796.

Guba, E., and Lincoln, Y. 1994. Competing Paradigms in Qualitative Research. In Denzin, N., and Lincoln, Y. (Eds.). (2005). The Sage Handbook of Qualitative Research (2nd ed.). London: Sage.

Hancock, M., and Morris, R, 2013. A review of further education and sixth form college governance: Report on findings and recommendations. Department for Business $\begin{array}{lll}\text { Innovation } & \text { and }\end{array}$ London:BIS.https://www.gov.uk/government/uploads/system/uploads/attachme nt_data/file/211285/bis-13-970-review-of-further-education-and-sixth-formcollege-governance.pdf. Accessed15/3/2016.

James, D., and Biesta, G. 2007. Improving learning cultures in further education London: Routledge Falmer.

King, N., and Anderson, N. 2002. Managing Innovation and Change: A Critical Guide for Organisations. London: Thompson. 
Kostoff, R. 2003. "Stimulating innovation”, in L. V. Shavinina (eds), The International Handbook on Innovation, Pergamon, 388-400.

Kvale, S., and S. Brinkman. 2009. Interviews. Learning the Craft of Qualitative Research Interviewing. London: Sage.

Lyotard, J. 1979. The postmodern condition: A report on knowledge (G. Bennington and B. Massumi, Trans.). Manchester: Manchester University Press.

Mitchell, J. 2003, Emerging Futures: Innovation in Teaching and Learning in VET, Melbourne, Anta.

Mulcahy, D. 2004. Making managers within post-compulsory education: policy, performativity and practice, Research in Post-Compulsory Education, 9(2): 183202.

OECD and Eurostat, 2005, Oslo Manual. Guidelines for Collecting and Interpreting Innovation Data. Paris: OECD.

Orr, K. 2009. Performativity and professional development: the gap between policy and practice in the English further education sector, Research in Post-Compulsory Education, 14(4):479-489.

Parnham, J. 1998. Questioning governance in English further education: a comparative study of the English and American systems, Research in Post-Compulsory Education, 3(3): 297-310.

Perryman, J. 2006. Panoptic performativity and school inspection regimes: disciplinary mechanisms and life under special measures. Journal of Education Policy 21(2): $147-161$.

Perryman, J. 2009. Inspection and the fabrication of professional and personal processes. Journal of Education Policy 24(5): 609-629. 
Perryman, J. S, Ball, M, Maguire and A, Braun. 2011. Life in the Pressure CookerSchool League Tables and English and Mathematics Teachers' Responses to Accountability in a Results-Driven Era, British Journal of Educational Studies, 59(2): 179-195.

Schofield, A. 2009a, What is an effective and high performing governing body in UK higher education? London Leadership Foundation for Higher Education.

Schofield, A. 2009b. A review of governance and strategic leadership in English further education (London, AOC/LSIS).

Strauss, A. 1987. Qualitative Analysis for Social Scientists. New York: Cambridge University Press.

Strauss, A., and Corbin, J. 1998. Basics of Qualitative Research: Techniques and Procedures for Developing Grounded Theory. Thousand Oaks: Sage.

United Nations Department of Economic and Social Affairs. 2006. Innovations in Governance and Public Administration: Replicating what works. New York, UN. 